Eng., 3, 342 (1980)

2) Fujie, K., M. Takaine, H. Kubota and Y. Miyaji: J. Chem. Eng. Japan, 13, 188 (1980).

3) Hills, J. H.: Chem. Eng. Journal, 12, 89 (1976).

4) Ide, K., S. Kawabata and H. Shinohara: Kagaku Kogaku Ronbunshu, 2, 439 (1976).

5) Nishikawa, M., Y. Yonezawa, T. Kayama, K. Koyama and S.
Nagata: J. Chem. Eng. Japan, 9, 214 (1976).

6) Ohkawa, A., Y. Shiokawa, N. Sakai and K. Endoh: J. Chem. Eng. Japan, 18, 172 (1985).

7) Otake, T., S. Tone and K. Shinohara: J. Chem. Eng. Japan, 14, 338 (1981).

8) Shah, Y. T., A. A. Kulkarni and J. H. Wieland: Chem. Eng. Journal, 26, 95 (1983).

\title{
CORRECTION OF THE PAPER "SYNTHESIS OF DISTILLATION SEPARATION PROCESS WITH ENERGY INTEGRATION"
}

MASAAKI MURAKI AND TOYOHIKO HAYAKAWA

Industrial Engineering Dept., Tokyo Institute of Technology, Tokyo 152

\section{Dear Sir:}

We wish to call attention to recently discovered errors in Tables 5 and $\mathbf{7}$ and Fig. 5 of the paper "Synthesis of Distillation Separation Process with Energy Integration," published in J. Chem. Eng., Japan, 14, 233-238 (1981). These errors were caused by a bug in the computer program for subproblem optimization. Fortunately, these errors have no serious effect on the conclusion of that study, and the effectiveness of the synthesis method proposed therein does not change. Tables 5 and 7 and Fig. 5 are revised, and the following additional corrections are necessary.

Page Column Line Erroneous Should be read

\begin{tabular}{ccccc}
\multicolumn{5}{l}{ (b, bottom; t, top) } \\
237 & 1 & $24 \mathrm{~b}$ & 27 & 33 \\
237 & 1 & $18 \mathrm{~b}$ & 2.70 & 3.39 \\
237 & 1 & $17 \mathrm{~b}$ & $26.8 \%$ & $8.0 \%$ \\
237 & 2 & $14 \mathrm{~b}$ & $26.8 \%$ & $8.0 \%$
\end{tabular}

We regret any trouble caused readers who had interest in our paper. We are grateful to Prof. Z. Fonyo for bringing some comments on our paper to our attention.

Received April 4, 1985. Correspondence concerning this article should be addressed to M. Muraki.
Table 5. Several solutions of the subproblems

\begin{tabular}{ccc}
\hline \multirow{2}{*}{ Subproblem } & \multicolumn{2}{c}{ Annual cost $\left[10^{5} \$ / \mathrm{y}\right]$} \\
& Rathore et al. & This study \\
\hline $2-8$ & 1.7168 & 1.3888 \\
$4-6$ & 2.8900 & 2.2479 \\
$4-9$ & 2.4737 & 2.0664 \\
$4-14$ & 2.6149 & 2.4936 \\
$4-15$ & 2.6363 & 2.2014 \\
\hline
\end{tabular}

Table 7. Calculation results of most economical subproblems

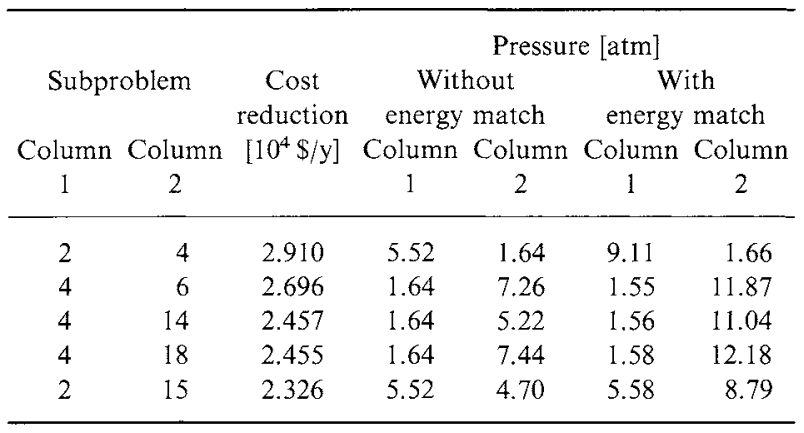

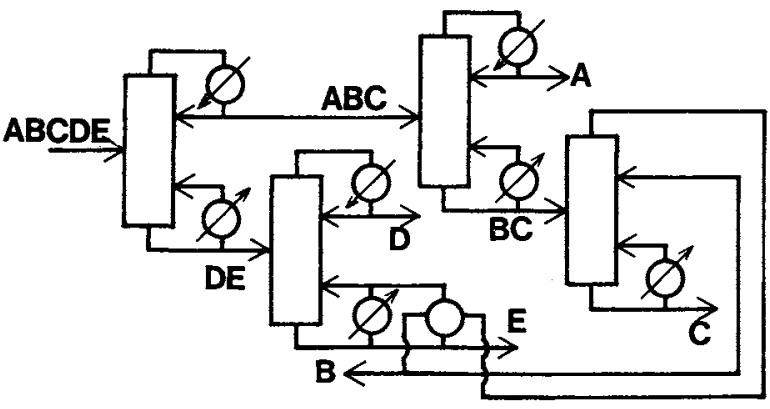

Fig. 5. An optimal distillation separation process with energy integration. 